\title{
Student Behavior Analysis to Predict Learning Styles Based Felder Silverman Model Using Ensemble Tree Method
}

\author{
Yunia Ikawati, M. Udin Harun Al Rasyid, Idris Winarno \\ Politeknik Elektronika Negeri Surabaya \\ Jl. Raya ITS - Kampus PENS, Sukolilo, Surabaya, 60111 \\ Email : yuniaa.ikawati@gmail.com, *udinharun@pens.ac.id, idris@pens.ac.id
}

Received December 29, 2020; Revised February 3, 2021; Accepted March 10, 2021

\begin{abstract}
Learning styles are very important to know so that students can learn effectively. By understanding the learning style, students will learn about their needs in the learning process. One of the famous learning management systems is called Moodle. Moodle can catch student experiences and behaviors while learning and store all student activities in the Moodle Log. There is a fundamental issue in e-learning where not all students have the same degree of comprehension. Therefore, in some cases of learning in E-Learning, students tend to leave the classroom and lack activeness in the classroom. In order to solve these problems, we have to know students' preferences in the learning process by understanding each student's learning style. To find out the appropriate student learning style, it is necessary to analyze student behavior based on the frequency of visits when accessing Moodle E-learning and fill out the Index Learning Style (ILS) questionnaire. The Felder Silverman model's learning style classifies it into four dimensions: Input, Processing, Perception, and Understanding. We propose a learning style prediction model using the Ensemble Tree method, namely Bagging and Boosting-Gradient Boosted Tree. Afterwards, we evaluate the classification results using Stratified Cross Validation and measure the performance using accuracy. The results showed that the Ensemble Tree method's classification efficiency has higher accuracy than a single tree classification model.
\end{abstract}

Keywords: E-Learning, Felder Silverman learning style model, Learning Style, Ensemble Tree Method.

\section{INTRODUCTION}

Education is one of the keys to human resource development. Advances in information technology make the education system also more developed. The rapid growth of Information Technology (IT), especially the internet, opens opportunities to develop better educational institutions' information services. E-Learning is a process of learning that uses technologies in the 
process of learning. Learning Management System (LMS) is one of the ELearning technologies [1]. Through LMS, students can access lecture materials, forums, chatrooms, and access lecture assignments given by lecturers [1]. Nowdays, one of the common learning management systems is Moodle. Moodle can record students' experiences and behaviors during online learning stored in the moodle log [2].

The problem in E-Learning is that students tend to leave the classroom and are less active. It is of particular concern; hence it is necessary to know students' preferences in the learning process by understanding each student's learning style. Students have different levels of understanding in the learning process [3]. The learning style refers to how students choose to be able to learn effectively. Along the students know the learning style, they will understand their needs in the learning process. Moodle unable to tell students' learning styles automatically. To determine the appropriate student learning style, it is necessary to analyze student behavior based on the frequency of visits when accessing Moodle E-learning and fill out a learning style questionnaire.

Based on these problems, this research uses the Felder Silverman model learning style approach based on four dimensions, namely Input, Processing, Perception, and Understanding, to map the learning style. We chose the Felder Silverman model because it is the most suitable learning style model in adaptive systems [4]. Felder \& Silverman's learning style model divides students' learning styles into four dimensions, namely Process (Active / Reflective), Input (Visual / Verbal), Perception (Sensitive / Intuitive) and Understanding (Sequential / Global). Active Learners prefer to join a group to solve problems, but Reflective learners prefer to work independently or in a small group. Sensing students are more interested in learning concrete facts and learning materials, but Intuitive students prefer to learn abstract learning materials. Visual learners interest in learning materials such as diagrams, drawings, and graphs, but verbal learners like to learn by reading or listening to information. Sequential students' interest in information is expressed in linear measures, but Global Learners use systematic and global approaches.

We propose a prediction model using Ensemble Tree method, namely Bagging and Boosting-Gradient Boosted Tree. A decision tree is a single tree algorithm, while an ensemble tree is a combination of several classifications. Ensemble Tree method solves class imbalance problems in the classification process [5][6] and improves machine learning algorithms' stability and accuracy [7][8]. Stratified Cross Validation is a variation of Cross-Validation that considers a class or group of data points. So we use Stratified Cross Validation to evaluate model performance. We compared the accuracy value between the Ensemble Tree method and the single tree classification model.

The research consists of: Part I describes the introduction of the proposed research. Part II presents a review of previous research on the algorithms used to classify learning styles and their parameters. Part III 
shows a review of the author's contributions and the originality of the study. Part IV describes the design system of research, data collection, data preprocessing, and applying the proposed methods. Part V discusses the performance of the proposed algorithm. Part VI contains conclusions.

\section{RELATED WORKS}

Some researchers have been conducted related to the prediction of student learning styles.

Hasibuan et al. [9] proposed to take into account the previous experience of students. The learning style prediction method uses the Neural Network algorithm and uses the Visual, Audio, Reading, and Kinesthetic (VARK) learning style. In this report, a total of 46 students participated.

Hoang et al. [10] suggested 3-layer Artificial Neural Networks (ANN) predict academic success based on learning styles.

Hasibuan et al. [11] implemented literature-based classification and predictive detection, regarded as a hybrid paradigm for identifying learning styles.

Wang et al. [12] proposed study to classify learning styles based on KMeans algorithms, analyze E-learning guidelines based on Page Rank algorithms, and analyze learning results.

Ouafae et al. [13] suggested an automated approach to identifying student learning styles based on web mining on moodle platforms. The process of classifying student log files corresponds to Felder and Silverman's learning style models. A total of 126 students have enrolled.

Ouafae et al. [14] implemented an adaptive e-learning framework. This study proposed an approach to the automated identification of learning styles based on the Felder and Silverman learning style models (FSLSM). The analysis consisted of two parts: the first part uses the K-means algorithm to divide it into sixteen FSLSM groups.

Manal et al. [15] proposed learning styles based on log data analysis using a Decision Tree relating to the FSLSM learning style. The study of this log data is focused on the navigation of the moodle students of e-learning. The result is a comparison of student quiz data and logs data. A total of 35 students participated. The accuracy result is $76 \%$.

Ling et al. [16] suggested a Bayesian Tree augmented naive to enhance the identification of learning types. The detection process begins with defined learning types. In compliance with the Bayesian augmented naive tree, change and update the learning style, totalling 46 participants in this research for seven weeks.

Renato et al. [17] compared several classifiers such as Naive Bayes and the Decision tree in classifying students' learning styles in the Virtual Learning System. This study uses 108 students of Computer Programming courses using Moodle. They are using a model of the Felder-Silverman Learning Style. For its assessment, this analysis used ten cross-validations. 
They measure the performance of each classifier using kappa classification and accuracy.

Keeley et al.[18] suggested a new method that uses a fuzzy decision tree to construct a collection of fuzzy prediction models that combine these variables into all of the Felder Silverman Learning Style model dimensions. This study is focused on 75 undergraduate university students. This research compared the proposed approach to the decision tree. Get the best results when using the fuzzy decision tree process.

Sheeba et al.[19] proposed approach predicts student learning references based on three dimensions of FSLSM learning: processing, perception, and input. This experimented with 300 students. This approach uses an updated decision tree classifier, designed with strict decision-making guidelines, to be precise. The outcome shows that the modified decision tree's classifier produces better precision than the decision tree's standard classification.

Hanan [20] compared classification strategies such as ANN, Decision Trees, Support Vector Machines and Naïve Bayes to predict student results. Two thousand thirty-nine students are using this research at the Computer Science and Knowledge Campus. Artificial Neural Network (ANN) models achieve the best accuracy from other models.

Waropat et al. [21] suggested classification of Ensemble using voting to model learning styles by integrating Neural Networks and K-Nearest Neighbor. The ensemble approach is better than other classifications in terms of precision.

Many use classification algorithms, including Decision Tree, Neural Network, and Bayesian Network, based on several similar studies for learning style prediction. The Decision Tree algorithm is used in this research because it is an algorithm that is easy to apply and highly reliable based on decision rules. The decision tree is an algorithm for a single tree. It may be an issue to use one decision tree which may not be robust enough. Previous analysis has found that the precision of the decision tree is less significant [15][17-20]. Then it would be convenient to use to merge the approach with multiple decision trees. It is called ensembling [21] to combine multiple classifiers in a prediction model. In the classification process, the ensemble approach solves class imbalance problems [5][6] and increases the stability and accuracy of machine learning algorithms [7][8]. Therefore, this analysis suggests the Ensemble Tree approach to predict learning style, where other researchers have not used the Ensemble Tree method for prediction of learning style especially Boosting-Gradient Boosted Tree.

\section{ORIGINALITY}

This study proposes how to dynamically detect learning styles based on Moodle's student behaviour analysis. The results of the behavioral analysis will be compared with the results of the Index Learning Style questionnaires based on the Felder Silverman Learning Style Model. The process of mapping 
the learning style using the Felder Silverman model's learning style approach is based on four dimensions: Input, Processing, Perception, and Understanding. Data mining is processed from student behavior analysis using Python programming. The mechanism of learning style prediction uses the Ensemble Tree system, respectively Bagging and Boosting-Gradient Boosted Tree. Ensemble Tree combines the classification of predictions from several models. The stability and precision of machine learning algorithms can be enhanced by this approach. Ensemble Tree can overcome instability in complex models with relatively small datasets. To evaluate model performance, Stratified Cross Validation is used. Stratified Cross Validation is a K-Fold variance that randomizes information based on a subset of training data and test data. It divides the data into n_splits that considers the class or group of data points. For example, the dataset is selected ten fold, divided into ten subsets, one subset as evaluation data, and the rest as training data. This method is replicated ten times, and the test data is different from the current subset. We compared the accuracy value between the Ensemble Tree method and the single tree classification model to measure performance.

\section{SYSTEM DESIGN}

In this study, we divided the process into four stages: (1) data collection, (2) data pre-processing, (3) classification model, and (4) analysis as shown on figure 1 .

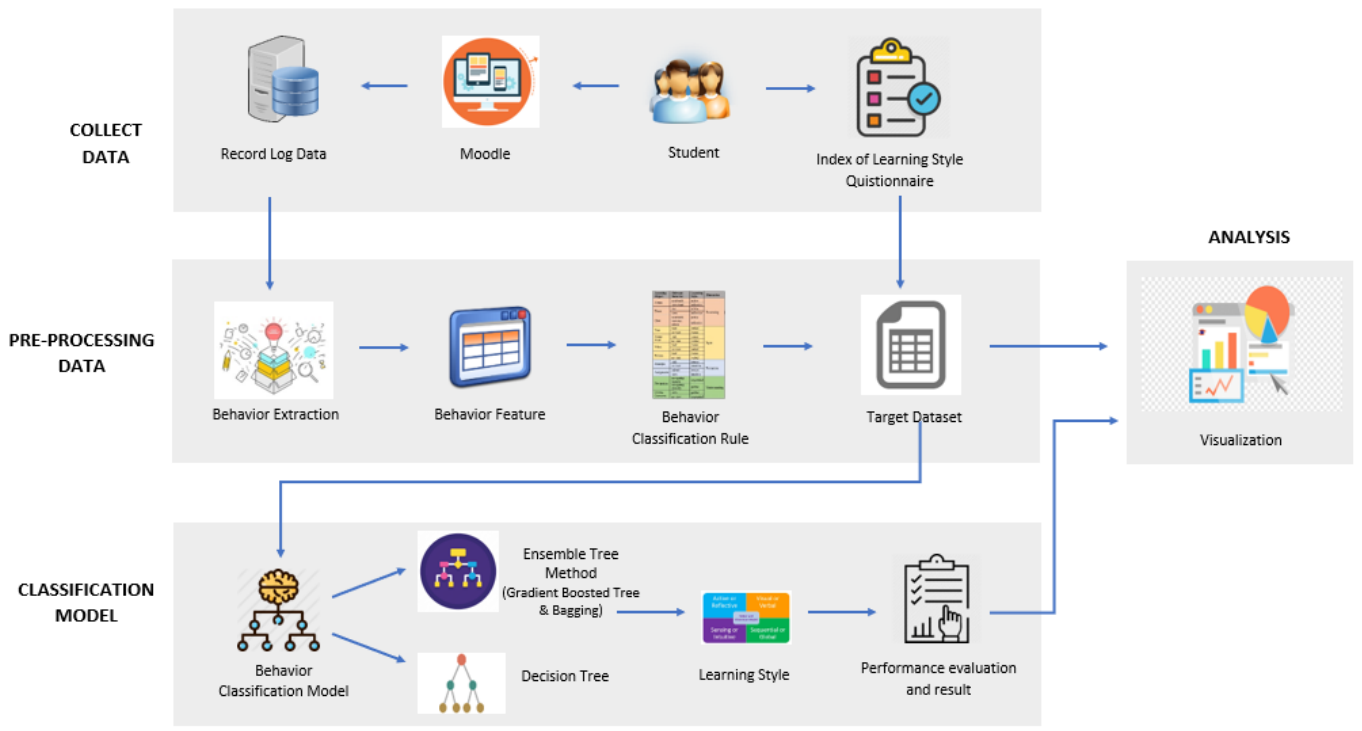

Figure 1. System Design

\subsection{Data collection}

The first step is the data collection process. To assess their preferred style based on the Felder and Silverman learning style questionnaire, for the first time, students have to fill out Index Learning Style questionnaires on the website https://www.webtools.ncsu.edu/learningstyles/. This questionnaire 
is made up of 44 questions. Besides, this research used the Moodle log data file at Lamongan State Community Academy (AKN Lamongan) for one semester in the Wireless Network course at the site address http://elearning.aknela.ac.id/moodle/. There are 65 students interested in this study with a major in Informatics Engineering, and they have access to Moodle for one semester. During Moodle entry, all student activities will be stored in the log data (2048 records in total). The Index Learning Style (ILS) questionnaire data gathered from Moodle will also be correlated with learning style findings from students' actions towards e-learning in this research. Figure 2 shows the course content of the Moodle E-learning.

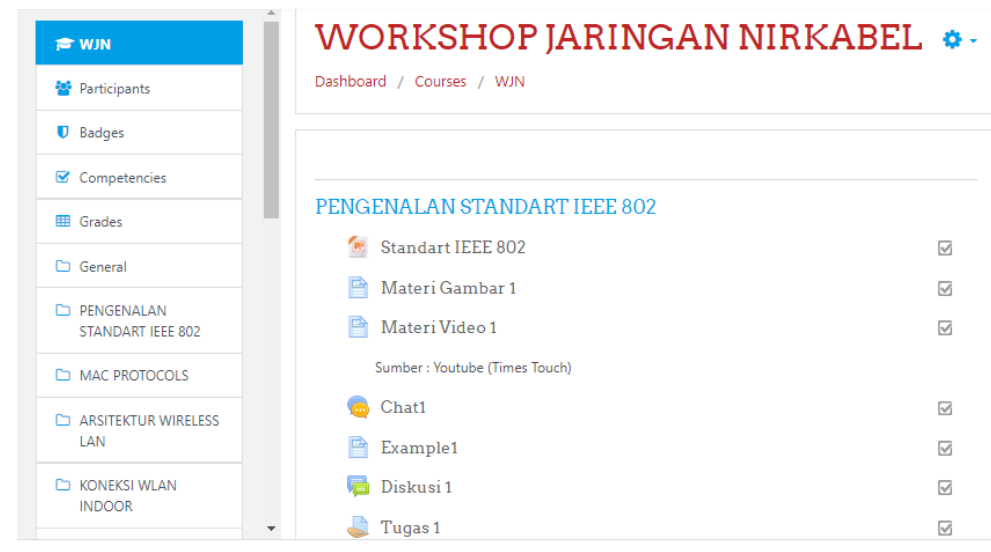

Figure 2. course content of the Moodle E-learning.

Based on figure 2, the material presented is adapted to Felder and Silverman's Model Learning Style Mapping.

\subsection{Pre-Processing Data}

It is a process to process raw data into quality data. The PreProcessing process consists of three parts: Student Behavior Data Extraction, Behavior Feature, and Behavior Classification Rule.

\subsubsection{Student Behavior Data Extraction}

The extract process is the first stage of the pre-processing data system. The extract selects and retrieves data from one or more sources (e.g., database) and then accesses the data retrieved. Data extraction is a method for extracting information from the Moodle logs. There are nine attributes for each case documented in the Moodle logs: time, user full name, affected user, event context, component, event name, description, origin, IP address. This study focused only on the user attributes of full name, event context, event name, and description. It corresponds to student behavior analysis based on the rules of learning style in table 1 . Event context attributes and event names reflect student behavior on different objects accessible from Moodle, such as chats, assignments, course content, and forum discussions. Figure 3 shows the performance of the log data. 


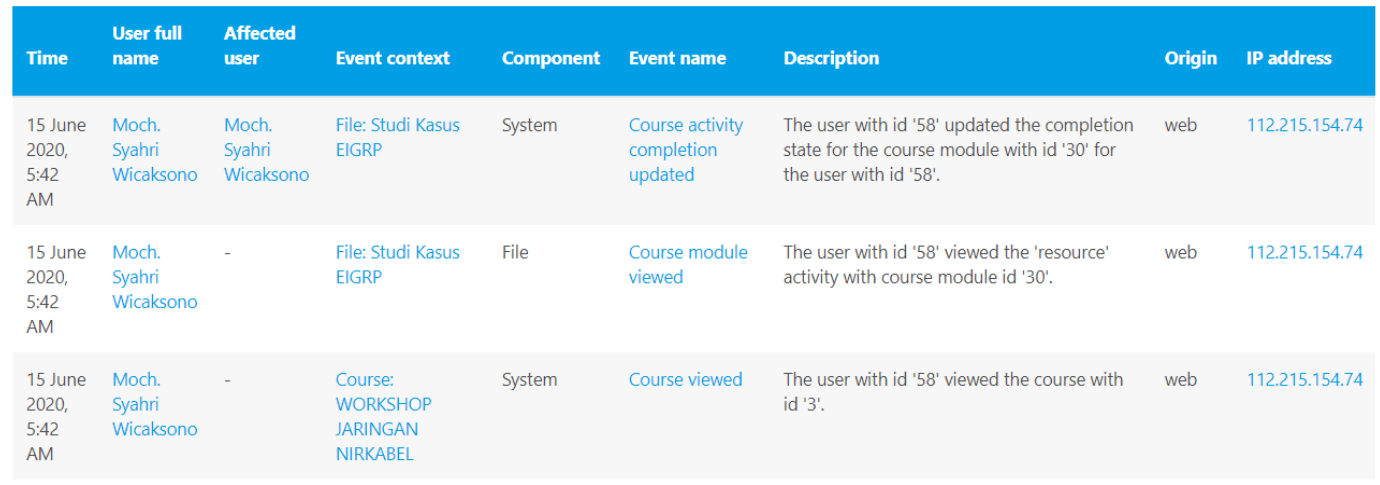

Figure 3. Moodle Log Data

\subsubsection{Behavior Feature}

Behavior Feature is the collection process of features appropriate for research purposes. This process is one of the data mining methods commonly used in the pre-processing stage. This technique is to reduce the complexity of the attributes to be used in the analysis process. This technique is to find out the most crucial feature subset of the data set. This process selects features that fit the FSLSM learning style's dimensions from Logs file data. We choose three features based on the research needs: user full name, event context, and event name.

\subsubsection{Behavior Classification Rule}

Behavior Classification Rule is a rule for classifying learning patterns based on student behavior. The features are mapped according to the FelderSilverman Model [22]. Based on the Learning Style Classification Rules, we can get a dataset pattern based on learning objects used as attributes/features based on FSLSM. FSLSM-based learning style divided into four dimensions, namely processing (active / reflective), input(verbal / visual), perception (sensor / intuitive) and understanding (sequential / global). Students who are classified to Processing dimension prefer to access learning object forums, demos, and chats. Students classified to Input dimension prefer to access the text of learning objects, pictures, videos, and powerpoint. Students who are classified to Perception dimensions prefer to access examples and assignments. Finally, students who are classified to Understanding dimensions based on navigation learning objects and course overview.

The target dataset is formed from data extraction based on the learning style classification rules in table 1 . Attributes in a data set are based on learning objects. The value of each variable is the cumulative frequency of visits by students to each learning object. Furthermore, identify the class based on their conduct towards e-learning for each student. Class are estimated based on the rules of classification of learning types in table 1, with the largest number of frequencies of each student on Moodle. 
Table 1. Proposed rules of learning style based on student actions

\begin{tabular}{|c|c|c|c|}
\hline $\begin{array}{l}\text { The object } \\
\text { of learning }\end{array}$ & Related behaviour & $\begin{array}{l}\text { Learning } \\
\text { Style }\end{array}$ & Dimension \\
\hline \multirow{2}{*}{ Forum } & post/reply & active & \multirow{6}{*}{ Processing } \\
\hline & view/read & reflective & \\
\hline \multirow{2}{*}{ Demo } & run & active & \\
\hline & view & reflective & \\
\hline \multirow{2}{*}{ Chat } & post/reply & active & \\
\hline & view/no-action & reflective & \\
\hline \multirow{2}{*}{ Text } & visit & verbal & \multirow{8}{*}{ Input } \\
\hline & no visit & visual & \\
\hline \multirow{2}{*}{ PowerPoint } & visit & visual & \\
\hline & no visit & verbal & \\
\hline \multirow{2}{*}{ Video } & visit & visual & \\
\hline & no visit & verbal & \\
\hline \multirow{2}{*}{ Picture } & visit & visual & \\
\hline & no visit & verbal & \\
\hline \multirow{2}{*}{ Example } & visit & sensor & \multirow{4}{*}{ Perception } \\
\hline & no visit & intuitive & \\
\hline \multirow{2}{*}{ Assignment } & submit & sensor & \\
\hline & view & intuitive & \\
\hline \multirow{2}{*}{ Navigation } & navigating linearly & sequential & \multirow{4}{*}{ Understanding } \\
\hline & navigating globally & global & \\
\hline \multirow{2}{*}{$\begin{array}{l}\text { Course } \\
\text { Overview }\end{array}$} & view & global & \\
\hline & no view & sequential & \\
\hline
\end{tabular}

\subsubsection{Classification Model}

Data Classification is the process in data mining to find a model or function that describes and distinguishes data into classes. Classification involves checking an object's characteristics and inserting an item into one of the previously defined categories. The classification process uses a supervised learning algorithm. In this study, data classification using Ensemble Tree is Gradient Boosted Tree and Bagging. We will compare Ensemble Tree Algorithm and Decision Tree Algorithm.

\section{A. Decision Tree}

Prediction models use tree structures or hierarchy structures. A Decision Tree is a classification method in data structures to analyze, recognize, and decide on unique behaviors [23], [24].

The tree's decision steps start by transforming the training data to the tree, the tree consisting of nodes, to decide the location of each node using the Entropy value $S$ defined in equation 1. 
$\operatorname{Entropy}(s)=\sum_{i=1}^{k}-p_{i} \log _{2} p_{i}$

Where:

$S=$ set (dataset) of cases

$k=$ number of partitions $S$

$\mathrm{p}_{\mathrm{i}}=$ proportion $\mathrm{S}_{\mathrm{i}}$ to $S$

Choosing the right segmentation variable from a data attribute in the decision tree can be calculated using each attribute-depending gain on the different values taken by this attribute, as shown in equation 2 .

$$
\mathrm{G}(\mathrm{S}, \mathrm{Q})=\mathrm{E}(\mathrm{S})-\sum_{\mathrm{i}=1}^{\mathrm{k}} \frac{\left\|\mathrm{S}_{\mathrm{i}}\right\|}{\| \mathrm{S} \rrbracket} \cdot \operatorname{Entropy}\left(S_{\mathrm{i}}\right)
$$

$$
\begin{aligned}
& \text { Where: } \\
& G=\text { gain } \\
& S=\text { set (dataset) of cases } \\
& k=\text { number of partitions } S \\
& \left|\mathrm{~S}_{\mathrm{i}}\right|=\text { proportion } \mathrm{S}_{\mathrm{i}} \text { to } S \\
& |S|=\text { number of cases in } S
\end{aligned}
$$

\section{B. Bagging}

Bagging can enhance the accuracy of learning algorithms by building a series of predictive functions and then combining them into predictive functions in a certain way [25]. Bagging proved sensitive to minor changes in training sets that were useful for improving classification accuracy from early decision tree classifiers by reducing variant misclassification.

In Bagging, large data sets are divided into smaller segments. Bagging uses equation 3 to calculate the final result of the classification.

$$
\mathrm{e}=\frac{1}{\mathrm{~N}} \sum_{\mathrm{i}=1}^{\mathrm{N}} \mathrm{e}_{\mathrm{i}}
$$

Where:

$e=$ final result of classification

$N=$ number of classification models

$i=$ classification order

C. Gradient Boosted Tree

Gradient boosted tree is the ensemble method of the classification tree. The ensemble comes from a decision tree model. The tree was added one by one to the ensemble and adapted to correct prediction errors made by 
previous models [26]. It is an advanced learning ensemble method that obtains predicted results through gradually improved estimation.

Gradient Boosting Tree uses equation 4 to calculate the final result of the classification.

$$
e=\sum_{i=1}^{N} w \cdot e_{i}
$$

Where:

$e=$ final result of classification

$N=$ number of classification models

$w=$ weight (weight calculated by considering the last iteration)

$i=$ classification order / iteration

Boosting trains models whose classification results are weak to be optimal. So it can be said that boosting combines some weak data to obtain vital data by training models sequentially.

\subsubsection{Analysis}

This section analyzes the results of new data sets from previous processes and analyzes model classification results. Several parameters are analyzed, namely each student's learning style, learning objects that are often accessed by each student, and the comparison of several classification algorithms to predict learning styles.

\section{EXPERIMENTS AND ANALYSIS}

This section outlines Moodle's approach to detecting learning styles based on an interpretation of student behavior. Next, compare the results of learning style detection to the ILS results of student questionnaires and analyze the results of learning style predictions using the proposed algorithm.

\subsection{Analysis of the proposed learning style detection}

To evaluate the learning model outcomes using the suggested approach, to classify FSLSM-based learning styles by evaluating student activity based on the number of visits to Moodle. Furthermore, comparing the results of student behavior analysis with ILS questionnaire as the reference [27]. It is because ILS questionnaires are instruments often used to identifying learning patterns based on the FSLSM.

The process of extracting Moodle logs in E-Learning produces a target dataset of learning style detection results focused on the frequency of student visits to E-Learning. The dataset labels are the largest total number of frequencies of each student on the Moodle. Figure 4 shows the target dataset formed. 


\begin{tabular}{|c|c|c|c|c|c|c|c|c|c|c|c|c|}
\hline Student & Forum & Demo & Chat & Text & PowerPoint & Video & Picture & Example & Assignment & Navigation & Course Overview & Class \\
\hline Achmad Munullij Ilhami & 0 & 0 & 0 & 3 & 8 & 4 & 5 & 0 & 0 & 0 & 0 & input \\
\hline Aida Riski Firman Syah $\mathrm{H}$. & 0 & 0 & 0 & 5 & 3 & 4 & 3 & 0 & 1 & 0 & 0 & input \\
\hline Aji Santoso & 6 & 2 & 7 & 0 & 1 & 0 & 0 & 1 & 0 & 0 & 0 & processing \\
\hline Ayu Ambarwati & 0 & 0 & 0 & 1 & 5 & 2 & 6 & 0 & 0 & 0 & 0 & input \\
\hline Bagas Hadi Prastyo & 0 & 0 & 0 & 0 & 1 & 0 & 1 & 3 & 6 & 0 & 0 & perception \\
\hline Bayu Ibrahim & 0 & 0 & 0 & 1 & 5 & 2 & 3 & 0 & 0 & 2 & 2 & input \\
\hline $\begin{array}{r}\text { Dian Anggraini Indah Puspita } \\
\text { Sari }\end{array}$ & 0 & 0 & 0 & 2 & 3 & 4 & 5 & 0 & 1 & 0 & 0 & input \\
\hline Geby Citra Prastika & 3 & 1 & 5 & 0 & 0 & 0 & 0 & 0 & 0 & 0 & 0 & processing \\
\hline Haffiddudin Iham Pratama & 0 & 1 & 0 & 0 & 0 & 0 & 0 & 5 & 2 & 0 & 0 & perception \\
\hline Harim Hawara Al Abid & 0 & 0 & 0 & 2 & 4 & 3 & 2 & 0 & 2 & 0 & 0 & input \\
\hline
\end{tabular}

Figure 4. Overview of the Target Dataset dashboard.

Here is a visualization of learning style results using analysis

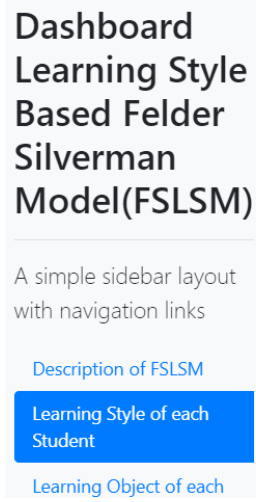

Dashboard Learning Style

Based Felder

Silverman

Model(FSLSM)

A simple sidebar layout

with navigation links

Learning Object of each

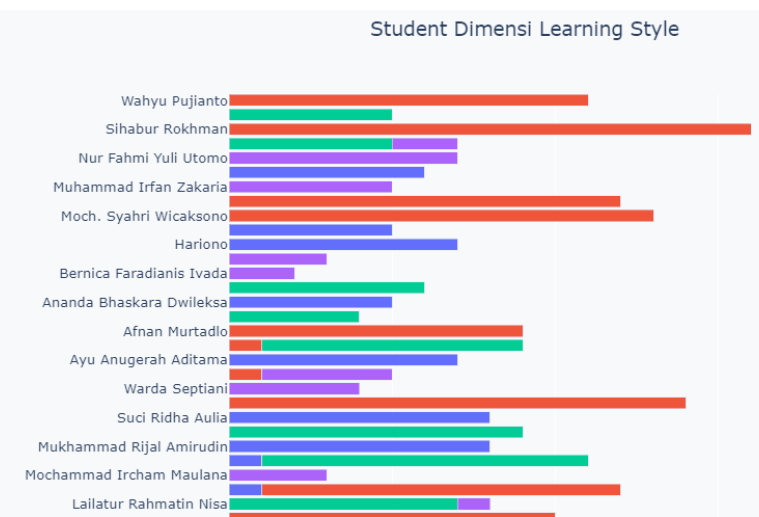

Figure 5. A Dashboard of the Student Learning Style

Figure 5 shows each student's learning style based on the dimensions of FSLSM. There is more than one dimension of learning style in the picture for each student. The learning style is selected based on the most significant number of measurements of the learning style. On the dashboard, when the pointer goes to one of the students, there will be data on the learning style dimensions, the frequency of grades, and the student's name.

\subsection{Evaluation of the proposed algorithm for predicting learning styles}

This study proposed the Ensemble Tree algorithm, Gradient Boosted Tree, and Bagging for the learning style prediction process. Next, match the results of the ensemble tree with a single algorithm Decision Tree. The classification process uses Python in Jupyter Notebook programming language. For performance evaluation of classification model/algorithm using Stratified Cross Validation. Stratified Cross Validation is a crossvalidation variant that splits data into two subsets: learning method data and validation data. that considers classes or groups of data points. It is suitable for small data samples consisting of more than one target class. We compared 
the number of K-Folds used in the classification process to determine which one is best: Fold 3, 5, 10 .

The accuracy is calculated to measure the classification model performance using equation 5 .

$$
\text { Accuracy }=\frac{\mathrm{TP}+\mathrm{TN}}{\mathrm{TP}+\mathrm{TN}+\mathrm{FP}+\mathrm{FN}} * 100 \%
$$

Where:

$\mathrm{TP}=$ True Positive

TN = True Negative

$\mathrm{FP}=$ False Positive

$\mathrm{FN}=$ False Negative

Table 2 and figure 6 show a comparison of the accuracy results of the proposed algorithm.

Table 2. Comparison of accuracy results

\begin{tabular}{|l|c|c|c|}
\hline \multirow{2}{*}{\multicolumn{1}{|c|}{ Algorithm }} & \multicolumn{3}{c|}{ Accuracy using Stratified K-Fold } \\
\cline { 2 - 4 } & $\mathbf{k = 3}$ & $\mathbf{k = 5}$ & $\mathbf{k = 1 0}$ \\
\hline Decision Tree & $82.10 \%$ & $84.20 \%$ & $84.30 \%$ \\
\hline Gradient Boosted Tree & $87.80 \%$ & $88.90 \%$ & $89.80 \%$ \\
\hline Bagging & $88.90 \%$ & $89.10 \%$ & $90 \%$ \\
\hline
\end{tabular}

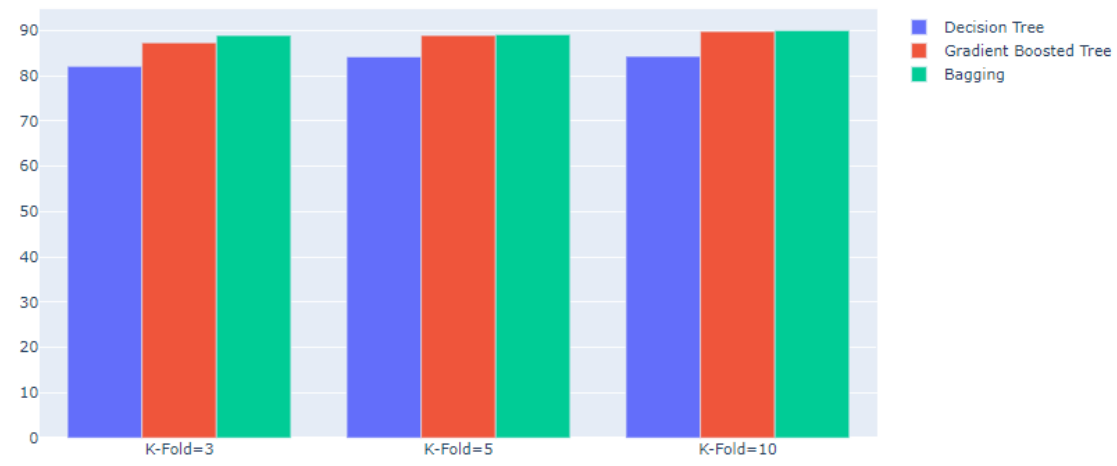

Figure 6. Comparison of measurement accuracy

Based on table 2, after conducting a classification experiment using the Decision Tree algorithm, Gradient Boosted Tree and Bagging using Stratified $\mathrm{K}$-Fold. The $\mathrm{k}$ value or the number of iterations is altered by the values 3,5 , and 10 . The highest accuracy is achieved when $\mathrm{K}=10$ with result using decision tree is $84.30 \%$, accuracy with gradient boosted tree is $89.80 \%$, and accuracy with Bagging is $90 \%$. The highest accuracy is achieved when using Bagging algorithm with $\mathrm{k}=10$ and gain accuracy $90 \%$ from these results. Based on the results of experiments in table 2 and figure 6, comparisons between single Decision Tree algorithms and ensemble tree algorithms 
(Gradient Boosted Tree and Bagging) for prediction showed that predictions using Ensemble Tree get higher accuracy value than a single algorithm. The Ensemble Tree method incorporates several classifiers in a prediction model that can reduce errors by reducing variance.

\section{CONCLUSION}

Students tend to leave the classroom and are less active when attending E-Learning. It is a problem in E-Learning, therefore it is necessary to know students' preferences in the learning process by understanding each student's learning style. Moodle can't automatically tell students' learning styles. To determine the appropriate student learning style, we can analyze student behavior based on the frequency of visits when accessing. In this research, we focus on analysis to determine learning patterns for students based on the learning styles of Felder and Silverman, which consist of 4 dimensions, namely Processings (Active / Reflective), Input (Visual / Verbal), Perception (Sensor / Intuitive), and Understanding (Sequential / Global). A simple web dashboard represents analytics defining learning styles to make it easier to visualize. Data analysis comes from log data in Moodle and compares the results of the study to ILS questionnaires. Furthermore, for learning style prediction, we propose an Ensemble Tree (Gradient and Boosting Tree) method using Stratified K-Fold, with values $\mathrm{k}=3,5$, and 10. It is more efficient for relatively small amounts of data and more than one target class if using a Stratified K-Fold. The results obtained are very satisfactory, namely the highest accuracy value when using $\mathrm{k}=10$ with Ensemble Tree Bagging algorithm that is 90\% accuracy. It proves that the use of the Ensemble Tree method is better than the Single Decision Tree Algorithm. For future research, we plan to increase the number of students involved in this research and develop research with other Ensemble Tree methods such as XGBoost Classifier, AdaBoost Classifier, and Extra Tree Classifier.

\section{Acknowledgements}

We would like to thank you for supporting this research to Lamongan State Community Academy of Politeknik Elektronika Negeri Surabaya (PENS).

\section{REFERENCES}

[1] Uday. K. Mothukuri, B. Viswanath Reddy, P. Naveen Reddy, Sarada Gutti, Improvisation of Learning Experience Using Learning Analytics in Elearning, IEEE National Conference on E-Learning \& E-Learning Technologies (ELELTECH), 2017.

[2] Yunia Ikawati, M. Udin Harun Al Rasyid, Idris Winarno, Student Behavior Analysis to Detect Learning Style in Moodle Learning Management System, IEEE International Electronics Symposium (IES), 2020. 
[3] Dwi Susanto, Qurani, N. R., M. Udin Harun Al Rasyid, Develop a User Behavior Analysis Tool in ETHOL Learning Management System, EMITTER International Journal of Engineering Technology, 2021.

[4] Birol Ciloglugil, Adaptivity based on Felder-Silverman Learning Styles Model in E-Learning Systems, IEEE International Symposium on Innovative Technologies in Engineering and Science (ISITES), 2016.

[5] Sajid Ahmed, Asif Mahbub, Farshid Rayhan, Rafsan Jani, Swakkhar Shatabda, Dewan Md. Farid, Hybrids Methods for Class Imbalance Learning Employing Bagging with Sampling Techniques, IEEE International Conference on Computational Systems and Information Technology for Sustainable Solution (CSITSS), 2017.

[6] Pumitara Ruangthong and Saichon Jaiyen, Hybrid Ensembles of Decision Trees and Bayesian Network for Class Imbalance Problem, IEEE International Conference on Knowledge and Smart Technology (KST), 2016.

[7] Giovanni Seni, John F. Elder, Ensemble Methods in Data Mining: Improving Accuracy Through Combining Predictions, Synthesis Lectures On Data Mining And Knowledge Discovery, 2010.

[8] Hasibur Rahman and Rabiul Islam, Predict Student's Academic Performance and Evaluate the Impact of Different Attributes on the Performance Using Data Mining Techniques, IEEE International Conference on Electrical \& Electronic Engineering (ICEEE), 2017.

[9] M. S. Hasibuan, L. E. Nugroho, P. I. Santoso, Detecting Learning Style Based on Level of Knowledge, IEEE Third International Conference on Informatics and Computing (ICIC), 2018.

[10]Hoang Tieu Binh and Bui The Duy, Predicting Students' performance based on Learning Style by using Artificial Neural Networks, IEEE 9th International Conference on Knowledge and Systems Engineering (KSE), 2017.

[11]M. S. Hasibuan and L. E. Nugroho, Detecting Learning Style Using Hybrid Model, IEEE Conference on e-Learning, e-Management and $e$ Services (IC3e), 2016.

[12] Wang Peng, Research on Online Learning Behavior Analysis Model in Big Data Environment, EURASIA Journal of Mathematics Science and Technology Education, Vol. 3, pp. 5676-5684, 2017.

[13] Ouafae El Aissaoui, Yasser El Madani El Alami, Lahcen Oughdir, Youssouf El Allioui, Integrating Web Usage Mining for an Automatic Learner Profile Detection: A learning style-based approach, IEEE International Conference on Intelligent Systems and Computer Vision (ISCV), 2018.

[14] Ouafae El Aissaoui, Yasser El Madani El Alami, Lahcen Oughdir, Youssouf El Allioui, A Hybrid Machine Learning Approach to Predict Learning Styles in Adaptive E-Learning System, International Conference on Advanced Intelligent Systems for Sustainable Development (AI2SD), pp. 772-786, 2019. 
[15]Manal Abdullah, Asmaa Alqahtani, Jawhara Aljabri, Reem Altowirg, Ruqiah Fallatah, Learning Style Classification Based on Student's Behavior in Moodle Learning Management System, Transaction on Machine Learning and Artificial Intelligence, Vol. 3, No. 1, 2015.

[16]Ling Xiao Li and Siti Soraya Abdul Rahman, Students' learning style detection using tree augmented naive Bayes, The Royal Society Open Science, 2018.

[17] Renato Maaliw III, Classification of Learning Styles in Virtual Learning Environment using Data Mining: A Basis for Adaptive Course Design, International Research Journal of Engineering and Technology (IRJET), Vol.3, No.7, 2016.

[18]Keeley Crockett, Annabel Latham, Nicola Whitton, On Predicting Learning Styles in Conversational Intelligent Tutoring Systems using Fuzzy Decision Trees, International Journal of Human-Computer Studies (IJHCS), 2016.

[19]T. Sheeba, Reshmy Krishnan, Prediction of Student Learning Style Using Modified Decision Tree Algorithm in E-Learning System, International Conference on Data Science and Information Technology, Pages 85-90, 2018.

[20]Hanan Abdullah Mengash, Using Data Mining Techniques to Predict Student Performance to Support Decision Making in University Admission Systems, IEEE Access, Vol.8, 2020.

[21]Worapat Paireekreng and Takorn Prexawanprasut, An Integrated Model for Learning Style Classification in University Students Using Data Mining Techniques, IEEE International Conference on Electrical Engineering/Electronics, Computer, Telecommunications and Information Technology (ECTI-CON), 2015.

[22]Richard M. Felder, Learning and Teaching Styles in Engineering Education, Journal of Engineering Education, 1988.

[23]J. R. Quinlan, Induction of decision trees, Machine learning, Springer, Vol. 1, No. 1, pp. 81-106, 1986.

[24]Xavier Amatriain, Alejandro Jaimes, Nuria Oliver, Josep M. Pujol, Data Mining Methods for Recommender Systems, Recommender Systems Handbook, Springer, 2011.

[25]Leo Breiman, Bagging Predictors, Machine Learning, No.24, pp. 123140, 1996.

[26]Jerome H. Friedman, Greedy function approximation: a gradient boosting machine, Ann. Statist, Vol.29, No.5, pp. 1189-1232, 2001.

[27]Richard M. Felder and Barbara A. Soloman, Index of learning styles questionnaire, Index of Learning Styles Questionnaire (ncsu.edu), s1997. 